\title{
LA SORPRESA DE BOLIVIA
}

\author{
Claudio Katz \\ CONICET, Universidad de Buenos Aires \\ (http://katz.lahaine.org/?page_id=5)
}

http://dx.doi.org/10.5209/rev_NOMA.2014.v44.n4.49289

\begin{abstract}
Resumen.- El modelo social-desarrollista ha generado en Bolivia un gran crecimiento sin transformaciones estructurales, desde un piso de gran subdesarrollo. La solidez electoral del gobierno deriva de logros democráticos previamente conquistados en las calles. Pero una nueva escala de avances enfrenta la coraza del capitalismo. El proyecto de socialismo comunitario se inspira en tradiciones vigentes, pero con menor proyección que en el pasado y enfrenta gran incompatibilidad con los escenarios internacionales de competencia. Estas mismas limitaciones afectan al estado plurinacional, que logró autoridad en todo el territorio a partir del desplazamiento de las elites racistas. El indianismo ha sido reemplazado por proyectos de convivencia más afines al ideal de diversidad político-cultural. El establishment comunicacional que maltrata a Venezuela ha sido considerado con Bolivia. Esta dualidad se extiende a otras incoherencias ideológicas de la derecha, que enfrenta en el Altiplano un gran límite para su contraofensiva regional.
\end{abstract}

Palabras clave.- Bolivia, indigenismo, marxismo, socialismo, desarrollismo.

\begin{abstract}
The social model-developmentalist has generated in Bolivia a great growth without structural transformations, from a floor very underdeveloped. The electoral strength of the government derives from democratic achievements previously conquered in the streets. But a new scale of progress faces the breastplate of capitalism. The community project of socialism is inspired by traditions, but with less projection than in the past and facing great incompatibility with the scenarios of international competition. These same limitations affect the plurinational state, that achievement authority throughout the territory from the displacement of the racist elite. Indianism has been replaced by coexistence projects more akin to the ideal of diversity political-cultural. The communicational establishment mistreating to Venezuela has been considered with Bolivia. This duality extends to other inconsistencies of the ideological right, facing in the Highlands a great limit to its regional counteroffensive.
\end{abstract}

Keywords.- Bolivia, indigenism, marxism, socialism, developmentalism.

Bolivia comparte con Venezuela el modelo económico social-desarrollista, la fisonomía nacionalista radical del gobierno y el ideario socialista, pero con modalidades muy distintas. También difieren los resultados y los balances que la prensa internacional difunde de la gestión de Evo Morales, en comparación a Chávez-Maduro.

El programa redistributivo fue aplicado en Bolivia con igual contundencia que en Venezuela. Se utilizó una renta energética (gasífera) para impulsar el consumo, mediante incentivos a la demanda orientados por el estado.

Como en el resto de América Latina este esquema fue dinamizado por el incremento de los precios de las materias primas exportadas. Los ingresos por estas ventas externas subieron de 2000 a 10000 millones de dólares por año.

Pero lo más significativo de Bolivia ha sido la elevada captación estatal de la renta generada por los combustibles. El incremento de las regalías absorbidas por el estado aumentó de 300 millones a 6000 millones de dólares al año. 
En la década precedente las finanzas estatales sólo capturaban el $18 \%$ de ese total y las empresas transnacionales se quedaban con el $82 \%$ restante. La nacionalización parcial de los hidrocarburos (2006) revirtió esta relación. Basta recordar la enorme incidencia de la venta de combustibles y minerales en el PBI boliviano, para mensurar esa mutación (Navarro, 2014).

Un giro semejante se verificó en Venezuela con la recuperación de PDVSA, pero la dimensión del cambio ha sido superior en Bolivia. En este país el estado se había quedado sin recursos y toda la renta se filtraba al exterior.

Las consecuencias económicas de esta transformación han sido mayúsculas. El gasto público se triplicó, el empleo público aumentó significativamente y los precios de los alimentos se estabilizaron.

Algunas estimaciones consideran que la mejora del salario mínimo alcanzó 64\% (2005-13), mientras que los bonos de asistencia cubren al 33\% de la población, en un marco de tarifas de electricidad y de combustible congeladas (Bárcena, 2014).

Otras evaluaciones destacan que la pobreza extrema urbana se redujo del $24 \%$ al $14 \%$ y su equivalente rural del 63 al $43 \%$. Los programas sociales han influido directamente sobre este resultado, a través de auxilios percibidos por todos los sectores marginados del mercado laboral. Hay bonos para los niños que van a la escuela (Juancito Pinto), para las mujeres que recién tuvieron familia (Juana Azurduy) y para los ancianos que nunca hicieron aportes jubilatorios (Renta Dignidad) (Molina, 2013).

\section{Avances desde el subsuelo}

Las mejoras sociales conquistas han sido semejantes a las registradas en Venezuela durante el primer período del modelo social-desarrollista. Pero una diferencia importante radica en el nivel de estabilización que logró este esquema en Bolivia. Este soporte se refleja en el creciente flujo de inversiones extranjeras directas.

La afluencia de divisas ha consolidado un elevado volumen de reservas (47\% del PBI), en un contexto de moderado endeudamiento público (35\% del PIB). La tradicional fuga de capitales que caracterizaba al país se detuvo y dio lugar a un incipiente proceso inverso (Bárcena, 2014).

Esta secuencia de crecimiento continuado diferencia al país de Venezuela. Bolivia lidera en los últimos años la tasa de crecimiento regional y esos resultados han generado un esperable elogio de CEPAL y una sorpresiva felicitación del FMI. El producto bruto pasó de 9.525 millones (2005) a 30.381 millones de dólares (2013) y el PBI per cápita saltó de 1.010 a 2.757 dólares.

Esta expansión se concretó con una baja tasa de inflación y una llamativa preocupación por preservar el equilibrio fiscal. Algunos analistas atribuyen ese resultado a un manejo prudente de las variables macro-económicas, como consecuencia del trauma legado por la hiperinflación del último gobierno de izquierda (1982-1985). También destacan la psicología campesina de Evo y su aversión al endeudamiento (Stefanoni, 2014).

En la gestión actual se ha priorizado la construcción de caminos, puentes y ciertos emprendimientos como el satélite Tupac Katari o el teleférico entre La Paz y El Alto. Estas obras recuperan la autoestima de una sociedad afectada por la ausencia de realizaciones.

¿El modelo social-desarrollista ha pasado la prueba? ¿Demostró su viabilidad? ¿Augura una siguiente etapa de superación del subdesarrollo?

Nadie se atreve a cantar victoria en una economía tan dependiente de la mono-exportación de combustibles. El Altiplano ha podido usufructuar más que otros países de la excepcional 
coyuntura de altos precios de las materias primas. Utilizó la renta generada por ese incremento para impulsar el consumo y redistribuir los ingresos.

Pero la ausencia de transformaciones productivas prende luces rojas para el futuro. Bolivia ha consumado avances que ya experimentaron en el pasado países más industrializados (como Argentina) o con estructuras medianas (como Venezuela) y enfrentará los mismos límites que encontraron esos antecesores.

El Altiplano parte de un piso muy bajo de subdesarrollo y cuenta con márgenes mayores para las expansiones rápidas. Pero ese retraso también determina un alto nivel de vulnerabilidad, en comparación con economías que cuentan con más recursos y capitales acumulados.

Los límites del modelo se vislumbran en la esfera de los hidrocarburos que financian todos los programas del estado. Luego de renegociar 44 contratos de concesión las compañías extranjeras mantienen considerables posiciones (especialmente REPSOL y PETROBRAS). La experiencia ilustra especialmente los peligros de utilizar los ingresos fiscales en subvenciones a los contratistas. La indemnización de 1045 millones de dólares recientemente concedida a la empresa Pan American Energy (por la expropiación de acciones realizada en el 2009) es una advertencia de esos antecedentes. Bolivia necesita todos sus recursos para procesos de industrialización (como la utilización del gas para elaborar fertilizantes y plásticos).

En el agro se verifican problemas semejantes. Comenzaron a normalizarse las situaciones irregulares que afectan a los dueños de las pequeñas parcelas. Pero la reforma agraria continúa demorada y la elevadísima concentración de la propiedad en un centenar de clanes terratenientes no se ha modificado.

\section{Inéditas conquistas}

El secreto de la estabilidad económica hay que buscarlo en la solidez del poder político construido por Evo Morales. Tras 8 años de gobierno, el líder del MAS conquistó en el 2014 un nuevo mandato, con un porcentaje de votos superior al $60 \%$. Ese resultado se ubica por encima de la victoria del 2005 y se aproxima al triunfo del 2009. Ha ganado en 8 de los 9 departamentos y logró mayoría en las regiones anteriormente adversas de Oriente (con ciertas pérdidas en sus bastiones del Altiplano).

Hasta ahora Evo ha podido sobrellevar el temido desgaste que genera el ejercicio del gobierno y mantiene la mayoría absoluta en ambas cámaras. Sus éxitos en los comicios se inscriben en el nuevo orden constituyente que introdujo a partir del 2006, luego de la aprobación de una nueva carta magna con el $72 \%$ de los sufragios.

Este nivel de fortaleza electoral no tiene precedentes en un país que tuvo 36 presidentes que no superaron el primer año de ejercicio. Evo será el mandatario más duradero de esa larga historia de fragilidades presidenciales. Ha logrado revertir la improvisada búsqueda de equilibrios entre las corporaciones que dominaba la vida política.

La consistencia que exhibe Evo contrasta con el desangre económico-social que sufrió Bolivia durante el largo período neoliberal iniciado en 1985. Esa nefasta etapa ha sido reemplazada por un aluvión electoral que convalida los triunfos previamente obtenidos por el pueblo en las calles.

Esa extraordinaria sucesión de luchas sociales fue comenzada por los productores de coca y posteriormente encabezada por los campesinos y trabajadores que libraron la guerra del agua. Derrotaron a los privatizadores, expulsaron a los concesionarios extranjeros y abrieron una gran secuencia de victorias desde abajo. Al costo de 77 muertos impusieron la huida del sanguinario Sánchez de Lozada. 
El gobierno de Evo surgió de estas batallas y se consolidó derrotando las conspiraciones de la derecha. Doblegó a los reaccionarios en las urnas, luego de aplastar la sublevación fascista del 2008 (masacre de Pando). Esa victoria explica la fortaleza de su administración.

Morales ha sido el único presidente de la región que surgió directamente de acciones insurgentes de los movimientos sociales. Por esta razón puso en marcha el contundente paquete de iniciativas democráticas y descolonizadoras que consagraron el establecimiento del estado plurinacional. La población indígena logró un reconocimiento sin precedentes de derechos colectivos para 40 etnias, en numerosos terrenos de la lengua, la cultura, la representatividad y la democracia participativa (Mayorga, 2014).

\section{Nuevos conflictos}

En pocos años se han introducido reformas políticas y sociales que Bolivia desconocía desde los años 50. La derecha tradicional presenta esas mejoras reales como simples fantasías retóricas. También señala que el gobierno populista desaprovechó el ventajoso escenario económico internacional. Le resulta inadmisible haber perdido el control sobre esos lucros y no logra entender cómo su derrota ha desembocado en un escenario de estabilidad capitalista.

Otros sectores conservadores optaron por subirse al carro victorioso del MAS. Incorporaron especialmente en Oriente una parte de sus viejas fuerzas (MNR, ADN) al oficialismo. Con esta absorción Evo logró mayoría en las zonas en disputa, pero hay sumas electorales que restan consistencia política. Esas ampliaciones nunca fueron gratuitas para los gobiernos populares (Arkonada Katu, 2014a).

Evo lidera un proceso reformista radical no sólo en el plano interno. También desenvuelve ese perfil a escala internacional, mediante impactantes cónclaves para exigir la defensa efectiva del medio ambiente, como la Cumbre de Cochabamba (Arkona, 2014b).

Lo más significativo de esa intervención geopolítica es una postura antiimperialista que desborda el terreno declarativo. La expulsión de los conspiradores yanquis (disfrazados de funcionarios de USAID) fue seguida de un retiro impuesto al embajador estadounidense que ha dejado vacante esa delegación. Además, los gobernantes de Israel fueron acusados de terrorismo de estado y el viejo reclamo a Chile de una salida al mar ha sido expuesto con gran contundencia frente a Piñera y Bachelet.

Morales promueve una ideología que combina nacionalismo con indigenismo. Comanda un sistema político que ha desplazado a la vieja elite de oligarcas blancos. Inició su gobierno prometiendo "transformar las protestas en propuestas" y proclama que Bolivia necesita "socios y no patrones".

Pero el desenvolvimiento de su proyecto enfrenta un techo muy estricto en los marcos del capitalismo. Hasta ahora su esquema concilió alivios populares con privilegios de las clases dominantes. Son dos metas en conflicto, que emergen a la superficie cada vez que el gobierno adopta alguna medida favorable a los grupos de poder.

En esos casos la reacción popular ha sido contundente. Ya ocurrió en diciembre del 2010 con el incremento de los precios de los combustibles ("Gasolinazo") y durante las marchas contra la construcción de una carretera que atraviesa territorios indígenas (TIPNIS).

El gobierno ha contemporizado con esas protestas y buscó resolver las tensiones en la mesa de negociación. Pero estos conflictos se acrecientan, a medida que Bolivia se transforma en una sociedad urbana con mayores exigencias sociales.

El capitalismo impide la satisfacción de esas nuevas demandas y reduce los márgenes para conciliar los intereses en pugna. Hasta ahora Evo logró soslayar estos problemas, pero no podrá eludirlos en el futuro. 


\section{Socialismo comunitario}

A diferencia de Venezuela el socialismo no está presente en Bolivia en los discursos oficiales, en las campañas electorales o en las exposiciones ideológicas corrientes de los gobernantes. Pero forma parte de la tradición política del país y de las principales organizaciones populares. El propio agrupamiento oficial (MAS) incluye la denominación socialista y Evo dedicó su reciente victoria electoral a Fidel y a Chávez, convocando a reafirmar la lucha contra el capitalismo.

El socialismo tiene cabida en otro plano, a través de la conceptualización teórica que ha desarrollado el vicepresidente García Linera. Su punto de partida es la crítica a los catastróficos efectos del capitalismo. Describe cómo este sistema multiplica la desigualdad, el desempleo y la destrucción de la naturaleza. Cuestiona el principio del beneficio, los efectos de la explotación y las agresiones del imperialismo.

Linera retoma el proyecto socialista como respuesta a ese escenario. Defiende ese modelo en términos tradicionales, polemizando con las distorsionadas interpretaciones que difundió la propaganda anticomunista. Recuerda que el capitalismo ha ocupado un breve lapso en la historia y destaca la vigencia del socialismo para superar los tormentos del capitalismo (García Linera, 2010a: 7-18).

Estas contundentes definiciones contradicen el planteo que expuso al asumir como segunda figura del gobierno de Evo. En ese momento propuso impulsar un modelo de "capitalismo andino-amazónico", tomando distancia de la convocatoria de Chávez a forjar el socialismo del siglo XXI. Sugirió que en Bolivia era conveniente la implementación de alguna variante económica del desarrollismo. Con sus nuevas definiciones a favor del socialismo parece revisar ese enfoque precedente.

Pero la peculiaridad del planteo de Linera radica en el perfil comunitario de su propuesta socialista. Subraya la vitalidad que mantienen las comunidades en Bolivia y la consiguiente vigencia de principios de trabajo asociativo, con fuertes valores éticos de fraternidad, tanto en el campo como los barrios populares de las ciudades.

El vicepresidente considera que esa continuidad permite gestar una variante de socialismo comunitario, semejante al aplicable en Ecuador o a ciertas zonas de México, India y África. Estima que este proyecto no es realizable en los países desarrollados (o de capitalismo intermedio), que han perdido toda memoria de las viejas formas económicas colectivas (García Linera, 2010a: 7-18).

Su propuesta está acotada a las regiones del planeta que conservan legados comunitarios. Linera no postula los proyectos generales de construcción cooperativista que impulsan las corrientes autonomistas. Tampoco propone crear comunas rurales, fábricas autogestionadas o economías del tercer sector como anticipos del socialismo. Se limita a señalar que el proyecto anticapitalista puede apoyarse en ciertos países, en la herencia legada por las antiguas estructuras comunitarias.

Esta tesis retoma la especificidad del socialismo andino que en 1920-30 intuyó Mariátegui. El intelectual peruano estimaba que el capitalismo había arrasado en su país con las comunidades incaicas del Ayllu. Pero también destacaba la subsistencia del espíritu solidario gestado por esa tradición. Convocaba a trabajar en la organización de una economía colectiva a partir de esos principios de comunismo agrario (Mariátegui, 2007: 119121).

Linera actualiza esa concepción y considera que su visión es coherente con la propia maduración de Marx, que en los últimos estudios de su vida remarcó las potencialidades revolucionarias de las comunidades agrarias rusas (Mir) (Kohan, 2000: 94-111). 
Pero los 140 años transcurridos desde esa caracterización han incluido intensos desarrollos capitalistas, procesos revolucionarios y ensayos de construcción socialista. El grado de subsistencia material de las comunidades en el siglo XXI es significativamente menor al observado por Marx o por Mariátegui. Aunque Linera pone el acento en el legado políticocultural y no en las estructuras económicas de esas formaciones, las mutaciones han sido muy grandes en todos los planos.

Existe otra significativa diferencia con esos antecedentes. Tanto Marx como Mariátegui formularon sus hipótesis, apostando a una victoria próxima del socialismo a escala mundial. Con esa perspectiva en mente imaginaban empalmes de los resabios del Mir ruso o del Ayllu peruano con pujantes desarrollos industriales de la periferia, apuntalados por las economías pos-capitalistas de Europa.

Linera reafirma esa eventual conexión entre un socialismo de raíces indígenas con el desenvolvimiento de alternativas anticapitalistas a escala mundial. Por eso rechaza cualquier ilusión de forjar un modelo socialista encerrado en el Altiplano. Pero también destaca que esa transición será un prolongado proceso de imprevisible duración (García Linera, 2008: 345-349).

En este esquema no aclara cómo se produciría el enlace de las antiguas formas comunitarias con el socialismo global. El cambio de temporalidad del proyecto no es un dato menor. La experiencia confirma que cuando esas modalidades quedan sujetas a un contacto dominante con el capitalismo se reduce significativamente la posibilidad de un empalme con cursos socialistas. La competencia mercantil, la generalización del trabajo asalariado y las inversiones del agro-negocio impiden esa convergencia.

Esta contradicción acentúa las propias ambigüedades del enfoque de Linera, que pondera la meta socialista sin abandonar su propuesta previa de capitalismo andino amazónico. Más bien sugiere algún tipo de coexistencia entre ambos esquemas, mediante fragmentos de capitalismo que convivirían con pedazos de socialismo. Supone que durante esa concordancia el segundo sistema erosionará gradualmente al primero (García Linera, 2010a: 7-18).

Pero no define cómo se consumaría esa transición. En sus textos evita precisar si concibe una tensión entre el mercado y la planificación durante el pasaje al socialismo o si proyecta un fortalecimiento previo del capitalismo, antes de cualquier comienzo socialista.

\section{Estados y Gobiernos}

Linera estima que el socialismo comunitario será precedido por una gran consolidación del estado. Considera que esa institución ha quedado sometida en la actualidad a un contradictorio proceso de mayor centralidad y vulnerabilidad. Puede manejar grandes presupuestos e intervenir con más contundencia en la economía, pero se encuentra más condicionada y sometida a los flujos internacionales del capital.

El vicepresidente entiende que para afianzar los derechos populares resulta indispensable fortalecer al estado nacional. Postula esta caracterización en abierta polémica con teóricos como Negri, que cuestionan ese propósito (García Linera, 2010b: 11-39).

Con este planteo Linera cierra su etapa de pensamiento autonomista. Pone fin a un período de expectativas en el protagonismo de los movimientos sociales y teorizaciones afines al concepto de multitud. Su llegada al gobierno implicó el abandono de esos conceptos y la adopción de una firme convicción en la centralidad del estado (Stefanoni, 2008: 9-26).

En esta nueva mirada la naturaleza de clase del estado es eludida. No se sabe si la institución que permitiría incorporar grandes derechos populares se inscribirá en una transición socialista o en el ámbito burgués. 
Linera subraya que en Bolivia el estado debe primero asegurar la descolonización, incorporando los derechos negados durante siglos a los pueblos indígenas. Describe cómo se avanzó en ese terreno legitimando toda la variedad de idiomas y culturas reconocidas en la nueva configuración plurinacional. Estima que este cambio constituye el punto de partida para sustituir el estado aparente de las minorías oligárquicas por el estado integral de las mayorías populares (García Linera, 2010b: 11-39).

En los hechos postula construir una estructura estatal sólida que ejerza su autoridad sobre todo el territorio. A diferencia del grueso de América Latina, esta construcción nunca fue completada en Bolivia. El gobierno de Evo ha intentado concluirla, creando una nueva red de funcionarios sustitutiva de las elites racistas precedentes.

Linera entiende que este paso será efectivizado por un gobierno popular, que en los hechos se desenvolverá en el marco capitalista. También aquí su planteo de socialismo comunitario queda diluido, ante la decisión práctica de preservar el régimen social vigente.

El vicepresidente también remarca la radicalidad del proceso boliviano, en comparación a otros países como Sudáfrica. Señala que allí se introdujeron drásticos avances descolonizadores con la eliminación del Apartheid, pero sin alterar la dominación económica de los grandes negocios. Considera que en Bolivia se consiguieron logros democráticos del mismo alcance, pero con nacionalizaciones y recuperación del poder económico del estado (García Linera, 2010: 11-39).

Esas medidas efectivamente incrementaron la captura estatal de la renta de los hidrocarburos, pero no iniciaron las transformaciones requeridas para una transición socialista. Linera evita evaluar esta limitación y sólo remarca la dimensión política del proyecto anticapitalista. Señala que esa estrategia requiere unidad de las organizaciones populares, seducción de las capas medias y aislamiento del imperialismo. Estima que en esas condiciones se podrá forjar gradualmente el socialismo (García Linera, 2010: 11-39).

¿Cómo concretar ese proceso? La gran popularidad y estabilidad del gobierno de Evo permite evitar estas preguntas. Pero no resuelve las dificultades que enfrentaron todos los procesos que siguieron el camino propuesto por Linera.

\section{Indianismo y marxismo}

Los indígenas ocupan un lugar prioritario en la nueva realidad boliviana. Linera remarca ese papel, recordando que Evo recupera un liderazgo perdido desde la época del Manco Inca (1540).

El vicepresidente resalta esta gravitación en polémica con los marxistas clásicos, que subrayaban el papel conductor del proletariado en las alianzas populares. Destaca el declive de la condición obrera, al calor de las transformaciones registradas en la minería. También remarca la incapacidad política de la vieja central sindical (COB) para adaptarse a este cambio y pondera el nuevo liderazgo indígena-campesino.

Esta visión de Linera proviene de su anterior proximidad con el indianismo katarista, que postulaba la reinvención del indígena como sujeto de la emancipación. El vicepresidente estima que esa gravitación quedó confirmada en la última década de bloqueos de caminos, que condujeron al surgimiento de una central sindical campesina (CSUTCB) (García Linera, 2008: 373-385).

Pero las conclusiones actuales de Linera no emergen sólo de esa trayectoria. También incorporan su alejamiento del katarismo. En los años 70 defendía las tesis indianistas, luego participó en la acción guerrillera y permaneció cinco años en la cárcel, manteniendo el ideario de autodeterminación de las naciones aimara y quecha. Pero el encuentro de su grupo (Comuna) con Evo luego de la guerra del gas, lo separó de ese pasado político. 
En la actualidad se sitúa en una vertiente integracionista del indianismo que reconoce la pluralidad y los aportes de la izquierda. Cuestiona la corriente culturalista (pachamámica) que promueve la simple folklorización y es crítico de la tendencia opuesta que propone construir una república india transnacional (en toda la región) o territorial (en Bolivia) (García Linera, 2008: 378-385).

El distanciamiento del katarismo y la aproximación al marxismo explican su caracterización actual del socialismo comunitario. Dejó atrás el programa de indianización total y participa en un gobierno que realza la gravitación de los indígenas, sin aceptar su separación del resto de sociedad. Esta visión de Linera tiene más proximidades con la izquierda mariateguista que con el indianismo katarista. Con este nuevo enfoque reformula el proyecto socialista manteniendo la centralidad de la cuestión indígena.

\section{Interrogantes de una evolución}

Las rebeliones sociales de la última década pusieron de relieve la opresión padecida en América Latina por 45 millones de individuos pertenecientes a 485 grupos étnicos distintos. Esta resistencia ha derivado en un significativo incremento del número de indígenas que auto-reconoce su identidad.

El último censo registró un gran aumento de la población que asume esa pertenencia. Agrupan al $8,3 \%$ de los habitantes de la región, pero constituyen el $62 \%$ de los habitantes de Bolivia. La enorme brecha que separa este porcentual del resto del continente (con la única excepción del $41 \%$ en Guatemala) explica la centralidad del problema indígena en el Altiplano (CEPAL, 2014).

Luego de siglos de avasallamientos, la convergencia de las demandas político-culturales de los indígenas con planteos antiimperialistas tradicionales ha generado nuevas síntesis políticas. Se ha demostrado que los oprimidos pueden asumir varias identidades, combinando aspiraciones culturales, nacionales y sociales (Katz, 2008: 23-28).

Linera inscribe su visión en este reconocimiento, tomando distancia del indianismo extremo. Su visión previa mantenía vínculos con una vertiente del esencialismo étnico que rechaza la existencia de estándares comparativos universales, para evaluar políticas y estrategias populares.

Ese enfoque realza la superioridad cultural de cierto grupo, mediante un atrincheramiento en las identidades que no deja lugar a la armonización y el entendimiento entre las distintas culturas. Objeta la insensibilidad liberal frente a la diversidad, pero reivindicando un particularismo que ignora el interés común de oprimidos (Díaz Polanco, 2006: 28-30).

El enfoque actual de Linera es más compatible con los ideales de la izquierda, que promueven la defensa conjunta de la igualdad y la diferencia. Marx alentaba el proyecto comunista y el anticolonialismo, Lenin auspiciaba el internacionalismo y el derecho a la autodeterminación nacional y Mariátegui apuntalaba el socialismo y el indigenismo (Díaz Polanco, 2006: 28-30).

Con su proyecto de socialismo comunitario el vicepresidente retoma la búsqueda de esos puentes entre indianismo y marxismo. Esta síntesis complementa varios cambios de su enfoque. Reemplazó las propuestas de autodeterminación por la prioridad del estado plurinacional y sustituyó el protagonismo de la multitud por un gobierno de movimientos sociales. Sus ideas iniciales de comunismo aldeano evolucionaron hacia una expectativa de capitalismo andino-amazónico, que actualmente ha devenido en un programa de socialismo comunitario.

Estas modificaciones tienen cierto parentesco con el itinerario intelectual de Chávez, que empezó coqueteando con la Tercera Vía, se relacionó con los militares derechistas 
argentinos, perfeccionó el nacionalismo militar revolucionario y terminó adoptando el socialismo.

La complejidad, riqueza y potencialidad de estas trayectorias no son registradas por las evaluaciones que simplemente acusan a Linera de mantener un razonamiento procapitalista y adverso a la revolución social (Ferreira, 2011).

Que el intelectual boliviano haya colocado el proyecto socialista en el centro de su estrategia no es un dato menor. El significado real de ese cambio quedará esclarecido con su evolución y su práctica política. A pesar de sus vaguedades, contradicciones e inconsistencias abre un terreno fértil para debatir la actualización del horizonte anticapitalista.

\section{Incoherencias de la derecha}

La derecha se burla de cualquier referencia al socialismo, considerando que apunta a entretener al electorado. Pero las menciones de su opuesto -el capitalismo- son vistas como consideraciones de gran trascendencia. Presenta la glorificación del mercado, la competencia o la ganancia como sinónimos de pensamiento profundo y ubica la defensa de la igualdad en un terreno de puro palabrerío.

Utilizando ese criterio ponderó la eliminación de todas las alusiones del MAS al socialismo durante la última campaña electoral. Atribuyó ese abandono al reforzamiento de un discurso conciliador y pro empresarial alejado de Venezuela (Guillemi, 2014). Pero esta interpretación no se condice con la dedicatoria del éxito electoral que hizo Evo a los pueblos que luchan contra el capitalismo

Es igualmente llamativa la diferencia de actitud que asume el establishment frente a Evo y Chávez-Maduro. El mismo tipo de socialismo que no entrañaría consecuencias para Bolivia es presentado como un terrorífico peligro para Venezuela. Ese temor es propagado por un pool de 82 periódicos latinoamericanos integrados a la SIP, que publica desde hace varios meses una página diaria de descripción del caos chavista.

Mientras que algunos medios anuncian el colapso final de la producción petrolera venezolana, otros retratan intenciones masivas de abandono del país (Oppenheimer, 2014; Vyas, 2014). Vargas Llosa encabeza esa campaña reaccionaria, proclamando la necesidad de acciones más contundentes que la simple protesta pacífica para derrocar al gobierno (Vargas Llosa, 2014).

La doble vara de la derecha frente a Bolivia y Venezuela no se basa en distinciones teóricas entre el socialismo comunitario (aceptable) y el socialismo del siglo XXI (indigerible). El problema de los conservadores radica en la dificultad para encontrar argumentos creíbles de ataque a Bolivia, luego de los logros conseguidos en la última década. El gobierno del MAS ha puesto de relieve el sistema político discriminatorio que ha regido en el Altiplano durante siglos y nadie se atreve a defender ese apartheid.

Por otra parte, el tamaño, los recursos y la gravitación regional determinan una incidencia geopolítica de Bolivia muy inferior a Venezuela. El imperialismo no se resigna a perder el manejo del principal territorio petrolero de América Latina y conspira para recuperar el control de PDVSA.

Estados Unidos no dudó en el pasado en invadir países más chicos que Bolivia (como Granada o Panamá) y mantiene desde hace décadas su asedio contra la isla de Cuba. Pero en la última década transformó a Venezuela en el eje del mal, porque este país demostró capacidad de desafío con la construcción del ALBA, la diplomacia del petróleo y la concreción de alianzas extra-regionales inadmisibles para el Departamento de Estado. 
El lugar que ocupa cada nación en los ataques imperiales cambia en cada coyuntura y no está determinado sólo por razones ideológicas. El gobierno de Argentina es agredido últimamente con la misma intensidad que su par venezolano, a pesar del explícito rechazo peronista de cualquier proyecto socialista.

La derecha diaboliza a ambos países, contrastando sus pesares con el bienestar imperante en el resto de Latinoamérica. Contrapone la excelente situación que atraviesan las naciones gobernadas por el neoliberalismo, con las desgracias sufridas bajo las administraciones populistas. Destaca como en Venezuela y Argentina se destruye la cultura del esfuerzo, el ahorro y la inversión por la politización del quehacer cotidiano (La Nación, 2014). También difunde datos que sitúan a ambos países al tope de los indicadores negativos de la región (Bazzan, 2014).

Con esas anteojeras ni siquiera registran las enormes diferencias que separan a las dos naciones. Mientras que en Venezuela la burguesía conspira para recuperar el manejo de renta petrolera, en Argentina la renta agraria está en manos del sector privado y sólo se disputa el monto de la tajada impositiva que absorbe el estado.

El modelo económico social-desarrollista de reformas sociales y redistribución del ingreso, que se ensaya en el primer caso difiere sustancialmente del programa neo-desarrollista de recomposición de la burguesía industrial, que se intentó en el segundo país. El chavismo confrontó con el imperialismo, movilizando a las masas y afrontando escaladas golpistas. En cambio el kirchnerismo sólo ha liderado una experiencia de centro-izquierda con autonomía de Estados Unidos, pero sin prácticas antiimperialistas.

El ataque indiferenciado de la derecha contra Venezuela y Argentina y su implícita consideración hacia Bolivia retrata la total inconsistencia de los mensajes derechistas. No explican cómo en el Altiplano se ha logrado una estabilidad macroeconómica bajo un régimen político liderado por caudillo, que reúne todas las pesadillas del populismo. Tampoco aclara de qué forma un gobierno tan alejado de sus formatos políticos ha logrado niveles de inflación, inversión o tranquilidad cambiaria semejantes a los países con gobiernos ultra-liberales.

La derecha realza a estas últimas administraciones ocultando los índices de exclusión, criminalidad o explotación. Nunca habla de la precarización laboral de Perú, del desastre de la jubilación en Chile o de la tragedia de los emigrantes de México y Centroamérica.

La omisión de noticias adversas en los países gobernados por la derecha, los silencios sobre Bolivia, las calumnias contra Venezuela y las campañas contra Argentina retratan cómo operan los medios de comunicación. Moldean un sentido común distorsionado para fijar la agenda pública al servicio de la dominación burguesa.

Los comunicadores de las grandes cadenas periodísticas nunca actúan con independencia, profesionalidad u objetividad. Aprovechan su condición de personajes influyentes para construir realidades virtuales divorciadas de los acontecimientos reales.

Por eso las batallas en este campo son decisivas y cualquier paso hacia la democratización del espacio comunicacional es vital. Desafiar el mensaje conformista, contrapesar la manipulación de las imágenes y demostrar que la información es un derecho en conflicto con la rentabilidad es una prioridad para la acción de la izquierda.

\section{Coyunturas y futuros}

El afianzamiento de un proyecto político radical con imaginarios socialistas en Bolivia retrata los límites de la contraofensiva actual de la derecha latinoamericana. Los conservadores buscan reinventarse con discursos más sociales, compromisos de asistencialismo y perfiles 
juveniles. Proclaman la disolución de las ideologías, despolitizan las campañas electorales y enfatizan la centralidad de la gestión.

La derecha pretende aprovechar el estancamiento del ciclo de ascenso popular, que comenzó a fines de los 90 en Venezuela y alcanzó su máxima intensidad entre el 2000 y el 2005. La resistencia de Honduras, las marchas campesinas en Colombia, las protestas estudiantiles en Chile y el despertar juvenil en Brasil no tuvieron la dimensión de las rebeliones previas de Venezuela, Argentina, Bolivia o Ecuador que tumbaron gobiernos neoliberales.

Pero no es la primera vez en la historia latinoamericana que un fuerte despegue de revueltas populares es sucedido por un escenario de contragolpes e indefiniciones. Los equilibrios de los últimos años estuvieron muy influidos por la recuperación económica y la afluencia de divisas generadas por la revalorización de las exportaciones agro-mineras. Ambos fenómenos tienden a frenarse.

Nadie sabe qué rumbo adoptará la resistencia popular en los próximos años. Pero la situación actual de Bolivia ilustra cómo la experiencia de la última década ha creado un piso de convicciones ideológicas y definiciones políticas que elevaron el nivel de conciencia popular. Este acervo constituye el basamento para debatir las estrategias de la izquierda.

Estas reflexiones presuponen una revalorización del socialismo, en contraposición a la presentación derechista de este debate como un simple juego de palabras, en torno a etiquetas sin contenido.

Esa discusión permite destacar que América Latina no afronta sólo escenarios neoliberales - neo-desarrollistas, sino también posibilidades anticapitalistas. Las experiencias de Venezuela y Bolivia alimentan reflexiones sobre estrategias, ritmos y caminos al socialismo. También inducen a soñar con ese futuro.

\section{Referencias bibliográficas:}

ARKONADA, K., (2014a), "Hacia un nuevo orden contra-hegemónico", www.rebelion.org, 16/6.

- (2014b), "Sostener para profundizar, profundizar para sostener", alainet.org, 13/10.

BÁRCENa, A., (2014), "El modelo boliviano", Página 12, 6/7.

BAZZAN, G., (2014), “Argentina y Venezuela tienen las peores notas”, www.clarin.com, 31/8.

CEPAL, (2014)), Los Pueblos Indígenas en América Latina. Avances en el último decenio y retos pendientes, www.cepal.org, 22/9.

Díaz Polanco, H., (2006), Elogio de la diversidad, Siglo XXI, México.

FERREIRA, J., (2011), "Comunidad indigenismo y marxismo", Estrategia Internacional, n 27, marzo.

GARCíA LINERA, Á., (2008), La potencia plebeya: acción colectiva e identidades indígenas, obreras y populares en Bolivia, CLACSO.

- (2010a), "El socialismo comunitario": un aporte de Bolivia al mundo", Estado Plurinacional, www.vicepresidencia.gob.bo.

- (2010b), "La construcción del estado", Tres pensamientos políticos, UBA sociales publicaciones, Buenos Aires.

GuILlEMI, R., (2014) "Aciertos políticos y cuentas pendientes", "De la épica chavista a la prudencia chilena, la metamorfosis de Evo”, La Nación, 15/10. 
KATZ, C., (2008), Las disyuntivas de la izquierda en América Latina, Ediciones Luxemburg, Buenos Aires.

KoHAN, N., (2000), De Ingenieros al Che, Biblios, Buenos Aires.

LA NACIÓN, (2014), "Argenzuela”, www.lanacion, 30/8.

MARIÁTEGUI, J., (2007), "La revolución socialista latinoamericana”, El marxismo en América Latina, Antología. Editorial LOM, Santiago de Chile.

MAYORGA, F., (2014), "Entrevista”, www.ihu.unisinos.br, 13/2.

MolinA, F., (2013), “¿Por qué Evo Morales sigue siendo popular?”, Nueva Sociedad, n 245, mayo-junio.

NAvarRo, M. y CÁRcAmo, C., (2014), “El modelo", Página 12, 24/8.

OPPENHEIMER, A,, (2014),"Venezuela hacia la importación de petróleo", www.libremercado, $3 / 9$.

Stefanoni, P,, (2008), "Presentación", La potencia plebeya: acción colectiva e identidades indígenas, obreras y populares en Bolivia, CLACSO.

Stefanoni, P., (2014), "Evo, el ex villano", Sin Permiso, 19-10.

VARGAS LLOSA, M., (2014), "La libertad en las calles de Venezuela", cubademocraciayvida.org, 10/3.

VYAS, K., (2014), “Venezuela”, images.elmercurio.com, 29/8. 